\title{
A Review Article on “Fast Fashion”
}

\author{
Thirumurugan $\mathrm{V}^{1 *}$ and Darthy Agnell Mary $\mathrm{AC}^{2}$ \\ ${ }^{1}$ Assistant professor, Bannari Amman Institute of Technology, India \\ ${ }^{2}$ Student, Bannari Amman Institute of Technology, India
}

Submission: November 15, 2019; Published: January 07, 2020

*Corresponding author: Thirumurugan V, Assistant professor, Bannari Amman Institute of Technology, Tamil Nadu, India

\begin{abstract}
The articulation fast fashion implies insignificant exertion attire collections that duplicate current lavishness configuration designs. Snappy structure fulfils significantly held needs among energetic buyers in the industrialized world for luxury style, even as it exemplifies unsustainability. Examples run their course with lightning speed, with the present latest styles rapidly besting yesterdays, which have quite recently been consigned to the decline container. This article watches out for the normal uproar among fast structure shoppers, who consistently share a stress for common issues even as they appreciate buyer plans opposing to natural acknowledged systems. Obviously fit at compartmentalize, and free of conflicted fault, such clients see no sensible irregularity in their Janus-stood up to needs. Would extravagance have the option to shape, with clearly an emphasis on validness, and its concomitants respect for specialist and nature, support estimations of both quality and sensibility. Since individual character reliably progresses and requires a physically referential reconsidering of self to do in that capacity, we gauge that genuine instead of fake excess brands can, by chance, join the guidelines of structure with those of biological practicality.
\end{abstract}

Business. Among the two models the quick style model is entrenched, anyway the moderate design model is picking up significance as it disheartens bothersome intemperate utilization of apparel bringing about the waste reusing issues and danger to condition. The paper additionally peeps through the inward, miniaturized scale and large-scale components affecting the business condition of style industry and available resources to beat these elements to meet a definitive objective to set up effective association with clients with sensible benefit. The large-scale components are regularly alluded as PESTEL (political, financial, innovation, condition and lawful) factors. It has been brought up that among these PESTEL factors, directly the ecological variables and social elements of business morals are representing a genuine danger to the manageability of quick style model of the design business. The conventional showcasing and the board of quick style industry is encountering an unrest in light of the developing of online business. Since the presentation of online business, associations have had the alternative to use the Internet in reducing costs related with acquiring, administering supplier associations, streamlining coordination and stock, and making essential good position and powerful utilization of business re-building. Online business enables organizations to improve interchanges inside the production network and upgrade administration offering, in this manner giving opportunities to focused separation.

That may clarify why such huge numbers of internet retailing organizations converged in China as of late, for example, Joyo Amazon, Dingdong, Taobao, Vancl and 360 buys. This article takes Zara and Vancl in examination for contextual investigation to break down the achievement of the recently blending web-based retailing organization in brisk plan industry and raises proposition for Chinese fast style industry to stay forceful later on

Keywords: Ecological wellbeing; Occupational wellbeing; Global wellbeing; Environmental equity; Sustainability; fast fashion

\section{Introduction}

Design industry is a noteworthy industry. It representatives a great many individuals over the globe, and each individual in the globe is influenced by design industry some way or another. Lamentably, style industry and particularly quick design industry, which has been made uniquely in couple of decades, incorporates numerous issues thinking about condition, society and economy. From a worldwide perspective pretty much, every individual faces the results that those issues made, particularly condition related, if no enhancements in the business happen. Hence, it is imperative to solicit what the present state from the business is, the manner by which it will be influenced by supportability pattern and is manageability a preferred position or potentially a danger for the business. This subject is significant for future, since businesses and organizations ought to be imaginative. Without activities design industry can confront numerous issues later on. Design industry is hundreds of years old industry and style assumes significant job in individuals' life: with style and garments people can communicate and form patterns recounts to the tale of the various occasions and societies. Quick design, as referenced, is new wonder in a past filled with mankind, just existed couple of decades, and it has changed 
the importance of garments. At no other time has been garments been created this hugely and a brief timeframe as today. Style has turned out to be somewhat pointless and expendable for its client. Design is never again about independence; it is making gigantic measure of same attire for an enormous group of spectators.

Making of quick design is because of numerous elements. Important players during the time spent building up the idea of quick design are financial development, increment of populace and purchaser conduct. One could state that quick design organizations are profoundly subject to buyer conduct. As such, it is exceptionally determined by shoppers. In this manner, it is imperative for quick style organizations to know about buyers' purchasing conduct and conclusions. Along these lines, design industry should know about patterns in the market. Supportability in business world has increased expanded notoriety and has turned out to be fundamentally a driving pattern. The purpose for this is individuals are currently mindful of, for instance, human rights, conditions in apparel production lines, ecological difficulties and how those issues will influence the eventual fate of the globe, economies and social orders. Quick style is a worldwide industry and in the globalized world discovering data about organizations and their activities has turned out to be easy. Customers these days have significantly more data than couple of decades back. Because of expanded attention to manageability, it has turned into a necessity for a business world. In this way, all things considered, supportability will shape the design and quick style industry much further later on. The quick design industry is considered to need manageability in its activities. Truth be told, the improvement of the business in maintainability has not developed.

A considerable lot of the present issues in quick design happen in creating nations where numerous organizations have reappropriated their assembling. Two key issues in quick style are social and natural issues and those reflect to economy, also. The earth is exceptionally devoured by apparel generation process. Typically, the enactment in creating nations, is a ton diverse contrasted with western nations. Condition and human rights are not as worried as they would be, for instance, in Europe. Many quick design organizations guarantee that condition is considered in each procedure, however in all actuality organizations may not understand how a lot of each creation procedure will expend condition.

\section{Fashion as a Global Environmental Justice Issue}

The excess of quick style-promptly accessible, cheaply made attire-has made a natural and social equity emergency, asserts another paper from a specialist on ecological wellbeing at Washington University in St. Louis. "From the development of water-concentrated cotton, to the arrival of untreated colors into neighborhood water sources, to specialist's low wages and poor working conditions, the ecological and social costs associated with material assembling are across the board," said Christine Ekenga, aide teacher at the Brown School and co-creator of the paper "The Global Environmental Injustice of Fast Fashion," distributed in the diary Environmental Health. "This is a monstrous issue," Ekenga said. "The unbalanced natural and social effects of quick design warrant its arrangement as an issue of worldwide ecological shamefulness." In the paper, Ekenga and her co-creators-Rachel Bick, MPH '18, and Erika Halsey, MPH '18-declare that negative results at each progression of the quick design store network have made a worldwide natural equity problem. "While quick style offers buyers a chance to purchase more garments for less, the individuals who work in or live close to material assembling offices bear an unbalanced weight of natural wellbeing perils," the creators composed. Moreover, expanded utilization examples have made a great many huge amounts of material waste in landfills and unregulated settings. This is especially pertinent to low-and center salary nations (LMICs) as quite a bit of this waste winds up in recycled garments markets.

These LMICs frequently come up short on the backings and assets important to create and implement ecological and word related shields to ensure human wellbeing. In the paper, the scientists talk about the natural and word related dangers during material creation, especially for those in LMICs, and the issue of material waste. They likewise address various potential arrangements, including economical filaments, corporate maintainability, exchange approach and the job of the shopper. All inclusive, 80 billion bits of new dress are bought every year, meaning \$1.2 trillion every year for the worldwide style industry. Most of these items are collected in China and Bangladesh, while the United States devours more apparel and materials than some other country on the planet. Roughly 85 percent of the attire Americans expend, about 3.8 billion pounds every year, is sent to landfills as strong waste, adding up to almost 80 pounds for each American every year.

\section{Textile Waste}

Despite the fact that quick style offers the market with reasonable attire crosswise over various customer levels, each period of the array's lifecycle produces looming word related and ecological dangers. A decent case can be drawn from the polyester; a ware acquired from oil and is the dominating fiber utilized in the assembling procedure. Because of the consistent ascent of the design business, interest for these filaments has likewise risen fundamentally throughout the most recent decade. Actually, insights gave by the Technical Textile Markets demonstrate that interest for man-made filaments, prominently polyester has nearly multiplied in the course of the most recent decade and a half. The assembling procedure including the manufactured textures uses a lot of raw petroleum while additionally discharging risky natural mixes, hydrogen chloride, and corrosive gases. Clearly, these effluents contrarily sway the earth and can likewise prompt 
respiratory infirmities. Aside from the assembling procedure, cotton and the material squanders spinning around this item are harmful to the earth

\section{Social Justice}

The Multi-Fiber Arrangement (MFA) represented the world exchange materials and pieces of clothing from 1974 through 2004 [1], forcing quantities on the sum creating nations could fare to created nations. It lapsed on 1 January 2005 [2]. The MFA was presented in 1974 as a momentary measure planned to enable created nations to acclimate to imports from the creating scene. Creating nations have a characteristic preferred position in material generation since it is work escalated and they have low work costs. As indicated by a World Bank/International Monetary Fund (IMF) study, the framework has cost the creating scene 27 million employments and $\$ 40$ billion per year in lost fares. Nonetheless, the Arrangement was not negative for every single creating nation. For instance, the European Union (EU) forced no confinements or obligations on imports from the exceptionally poor nations, for example, Bangladesh, prompting an enormous extension of the business there. At the General Agreement on Tariffs and Trade (GATT) Uruguay Round, it was chosen to bring the material exchange under the purview of the World Trade Organization (WTO). The WTO Agreement on Textiles and Clothing accommodated the steady disassembling of the standards that existed under the MFA.

This procedure was finished on 1 January 2005 [2]. Be that as it may, huge duties stay set up on numerous material items. Bangladesh was required to experience the ill effects of the closure of the MFA, as it was relied upon to confront more challenge, especially from China. In any case, this was not the situation. Things being what they are, even notwithstanding other financial goliaths, Bangladesh's work is "less expensive than anyplace else on the planet." While some littler industrial facilities were archived making pay cuts and cutbacks, most scaling down was basically theoretical - the requests for merchandise continued coming even after the MFA terminated. Truth be told, Bangladesh's fares expanded in an incentive by about $\$ 500$ million of every 2006 [3].

\section{Sustainable Fibres}

\section{Recycled Cotton}

Cotton is one of the most widely recognized and most utilized textures (it speaks to almost a large portion of the texture utilized in the material business) [4]. This regular fiber is light and breathable which makes it a closet staple. Be that as it may, developing cotton can be tricky: traditional cotton is one of the thirstiest and most synthetic concentrated yields to develop. It requires a great deal of pesticides and, thus, negatively affects the planet, and the individuals who develop it. Natural cotton, a progressively practical option in contrast to customary cotton, has been blasting over the most recent couple of years. It plans to limit the natural effect of cotton generation by attempting to evacuate unsafe pesticides and different synthetics from the creation procedure [5-9]. Check if your natural cotton is GOTSaffirmed to guarantee elevated expectations underway. In case you're searching for the most practical cotton, notwithstanding, go reused. Reused or upcycled cotton is made utilizing postmechanical and post-shopper cotton squander. As per the Higg Materials Sustainability Index, reused cotton is an increasingly economical option in contrast to both customary and natural cotton. It can possibly help lessen water and vitality utilization, just as help keep cotton garments out of landfill - which is the reason we think of it as one of the most practical filaments available.

\section{Organic Hemp}

It appears as though hemp is wherever right now. Pot's 'calm cousin' is very adaptable: it's utilized as a nourishment, a structure material, in beautifying agents, and it has been developed and utilized for many years as a texture. The incredible thing about hemp is that it's developed all around the globe and it requires next to no water, no pesticides, and normally treats the dirt it develops in - improving it much for the earth than different yields. Probably the most seasoned fiber on the planet, hemp helps keep you warm in winter and cool in summer and gets gentler the more you wash it [10-13]. For every one of these reasons, we additionally consider hemp one of the most economical textures out there.

\section{Organic Linen}

Cloth is another characteristic fiber we've been developing for quite a long time. Like hemp, it's gotten from an exceptionally flexible yield: the flax plant. Material requires negligible water and pesticides, and even develops in low quality soil. Also, all aspects of the plant is utilized, so nothing is squandered. Material is solid, normally moth safe, and, when untreated (for example not colored), completely biodegradable. Notwithstanding being useful for the planet, it is additionally light and can withstand high temperatures, engrossing dampness without holding microscopic organisms. Characteristic, supportable textures have the benefit of being biodegradable and abstain from utilizing the plastics that go connected at the hip with the non-renewable energy source industry [14-16]. Only one out of every odd normal texture has made the rundown, be that as it may, with bamboo, fleece and cowhide bringing their own perplexing issues which mean we're mindful about prescribing them by and large. Design is about advancement, so what actions is the business taking to make new economical textures? Here are a portion of the new kinds of innovative manufactured filaments that have additionally made it onto our rundown.

\section{Corporate Sustainablity}

Corporate maintainability has turned into a trendy expression in organizations of all shapes and sizes. Wal-Mart Stores, Inc. (WMT), McDonald's Corporation (MCD) and huge numbers of the genuine corporate goliaths have named supportability as a key need pushing ahead [17]. (For additional, see: "Yum! 
Brands Believes in Sustainability.") Now different enterprises are experiencing strain to indicate how they intend to submit and convey their products and ventures in a manageable way. This, obviously, makes one wonder of what precisely this all methods. Corporate maintainability in speculation can fall under the terms ESG for condition, social, and administration or the abbreviation SRI which represents socially capable venture. Maintainability is frequently characterized as addressing the necessities of the present without trading off the capacity of future ages to meet theirs. It has three primary columns: financial, ecological, and social. These three columns are casually alluded to as individuals, planet and benefits. Corporate maintainability is a developing worry among speculators who look for monetary benefit as well as social great. ESG speculation speaks to the 3 mainstays of manageable contributing: natural, socially dependable, and administration. With the development of socially capable assets and ETFs, corporate manageability may at last add a focused edge to an organization's main concern [18-20].

\section{Impacts of Textile Waste}

It is evaluated that about $75 \%$ of the 2.35 million tons of apparel and material disposed of by customers in the UK winds up in landfills. An extent of that waste is produced using nonbiodegradable manufactured fiber; other regular strands do disintegrate yet delivering emanations of dangerous gases, for example methane or smelling salts during the procedure, which are contaminations to both air and water. As far as the other $25 \%$ of material waste that is recouped, they are either reused, fixed and reconditioned, or reused. Reuse, which includes gathering, arranging, and exchanging as recycled garments, "brings noteworthy natural investment funds". Fix and reconditioning require more assets as recovering, fixing, and updating the items need work and extra materials. Reusing utilizes assets the most, yet still not exactly delivering new things even with the most unpredictable procedures [21-23]. Be that as it may, Akko and Koskennurmi-Sivonen keep up that reusing materials expends vitality for the mechanical or compound handling of strands and repining them into new yarns, which means it is "a method for overseeing waste, yet not a method for decreasing it". Another issue related with material waste is the arrival of microplastic filaments, or microfibers, during local clothing of engineered strands, especially polyester. Microplastics, plastic particles littler than $5 \mathrm{~mm}$, are another poison found in freshwater and marine conditions. They can without much of a stretch enter airborne living beings, for example, microscopic fish and get ensnared in their stomach, subsequently decreasing bolstering action [24].

Besides, the ingestion of microplastics can prompt the retained synthetic concoctions being filtered, which thus become a wellspring of dangerous substances affecting the life forms and entering the evolved way of life upward to people. Perilous as they may be, microplastic filaments are discharged into the earth in each residential wash. Washing trials were led by various scientists in both front and top-load family unit clothes washers for polyester wool coats and sweaters, and it was found that there are around 0.16 to $2.7 \mathrm{~g}$ microfiber mass shaded per article of clothing per wash, with expanded shedding as pieces of clothing age. Moreover, the measure of microfiber mass recouped from top load machines is substantially more significant than that from front-load machines, which was seen as multiple times bigger by Hartline et al. in correlation with 2.7 occasions by Bruce et al. Despite the fact that this issue of microfiber contamination happens during the utilization period of customers, it is of noteworthy ramifications for design supervisors and producers regarding their utilization of materials and their procedure to moderate the effect of this kind of contamination.

\section{The Role of Consumer}

Frame of mind can be characterized as just and generally speaking assessment, and it typically assume a significant job in forming purchaser conduct. Disposition is valuable for advertisers from multiple points of view, for example, utilizing effort to positively affect demeanors, even without impacting deals, and utilizing mentality to portion markets and pick target fragments. Since the demeanor will assist the shoppers with shaping their last buy conduct. For our situation, it very well may be discovered that the customers as of now have a few frames of mind, or convictions, towards the two distinctive included quick design brands, H\&M and Gina tricot. From the observational finding of \#14, shoppers accept that H\&M has preferable quality over Gina tricot, and increasingly global, while Gina tricot is accepted to be progressively reasonable for more youthful young ladies with littler sizes, and updates at regular intervals, which the purchasers gain from its battles. Customers are additionally shaping their disposition during their expending in after-buy arrange. The observational finding of \#12 demonstrates that most quick design customers are commonly happy with the items they acquired in the past half year, however top to bottom despite everything they have some different inputs that can mirror their sentiments on the particular brands or items, which will affect their frames of mind and therefore impact the following buy conduct.

A few customers found the quick design items lost gloss rapidly, and some discovered they were not dependable products because of the quality isn't that great, or some vibe H\&M have preferred quality over Gina tricot. These emotions amass over a period and structures customers resembles and detest frame of mind

\section{Conclusion}

Fast Fashion and the way of life of dispensable things is a genuine match. The plan of action of quick style is overwhelmingly targeting offering the current "it" things existing apart from everything else with tolerable sticker price, empowering each customer to shop stylish pieces. Regardless, low quality and rapidly changing patterns have a basic impact with regards to 
disposed of materials. At the point when garments are not intended to last, yet are appealing enough for shoppers to purchase, the sad cycle of industrialism and over utilization is ensured, driving to immense measures of materials discarded. Significant issues concerning expendable thing society can be seen in solid industrialism and ecological harms. Disposed of materials bring out issues in waste dealing with as reusing choices for recycled quick style products are constrained. In this way, because of over the top overconsumption, our condition is in question; landfills continue heaping up while the materials utilized in quick design materials result in hundreds of a long time of biodegrading time. Dispensable things are not gainful for buyers either sincerealism progresses toward becoming a focal point to our lives while requiring impressive sum of cash for substitution purposes [25].

Fathoming the issue of disposable society with regards to quick design requires a ton of time, dynamic inclusion from worldwide quick design retailers and an extraordinary change in purchasers' purchasing propensities, joined with legislative acts. The issues in fast fashion are so huge at the minute yet at the same time yet imperceptible for some. The solid clothing which quick design oversees to make among purchasers is prominent to the point that the issues in the background are effectively rejected. Significant alter towards increasingly supportable course is required for better tomorrow.

\section{References}

1. Ailawadi K, Keller K (2004) Understanding retail branding: Conceptual insights and research priorities. Journal of Retailing 80(4): 331-342.

2. Park HH, Oh SD (2005) The influence of materialism and environment consciousness on recycling attitude and behavior of clothing. Journal of the Korean Home Economics Association 43(10): 167-177.

3. Esch FR, Langner T, Schmitt BH, Geus P (2006) Are brands forever? How brand knowledge and relationships affect current and future purchases. The Journal of Product and Brand Management 15(2): 98105.

4. Choi NS (1995) A study on the influence of environmental education and environmental consciousness to the environmental behaviour. Journal of the Korean Home Economics Association 32(5): 29-44.

5. Han SH (2009) A study on the purchasing behavior and usage of environmentally friendly clothing and the disposal of clothing. Journal of Korean Home Management Association 27(3): 61-77.

6. Kang JH, Sung YY (2010) The impact of information technology on the process innovation and competitiveness in the fashion industry -Case study of fast fashion: ZARA. Journal of the Korean Society of Clothing and Textiles 34(1): 1-13.

7. Shim S (1995) Environmentalism and consumers clothing disposal patterns: An exploratory study. Clothing and Textiles Research Journal 13(1): 28-48.

8. Shin MH (2011) The influence of fast fashion value on commitment and repurchase intention. Korea Business Review 24(6): 3505-3523.
9. Yoo YS (1996) A study on the women's clothing discard behaviour. Journal of the Korean Society of Clothing and Textiles 20(1): 42-156.

10. Brady A (2003) How to generate sustainable brand value from responsibility. Journal of Brand Management 10(4-5): 279-289.

11. Brengman M, Willems K (2009) Determinants of fashion store personality: A consumer perspective. Journal of Product and Brand Management 18(5): 346-355.

12. Brown T, Dacin P (1997) The company and the product: Corporate associations and consumer product responses. Journal of Marketing 61(1): 68-84.

13. Chattopadhyay A, Alba JW (1988) The situational importance of recall and inference in consumer decision making. Journal of Consumer Research 15: 1-12.

14. Chen YS (2008) The driver of green innovation and green image-green core competence. Journal of Business Ethics 81(3): 531-543.

15. Childs ML (2014) Is Uppsala model valid to fashion retailers? An analysis from internationalization pattern of fast fashion retailers. Journal of Fashion Marketing and Management 18(1): 36-51.

16. Claudio L (2007) Waste couture: Environmental impact of the clothing industry. Environmental Health Perspectives 115(9): 448-454.

17. Faircloth JB, Capella LM, Alford BL (2001) The effect of brand attitude and brand image on brand equity. Journal of Marketing Theory and Practice 9(3): 61-75.

18. Fombrun C, Shanley M (1990) What's in a name? Reputation building and corporate strategy. Academy of Management Journal 33(2): 233258.

19. Hur WM, Kim H, Woo J (2013) How CSR leads to corporate brand equity: Mediating mechanisms of corporate brand credibility and reputation. Journal of Business Ethics 125: 75-86.

20. Joseph WA, Chattopadhyay A (1985) The effects of context and partcategory cues on the recall of competing brands. Journal of Marketing Research 22(3): 340-349.

21. Joy A, Sherry JF, Venkatesh A, Wang J, Chan R (2014) Fast fashion, sustainability and the ethical appeal of luxury brands. Fashion Theory 16(3): 273-296.

22. Lai CS, Chiu CJ, Yang CF, Pai DC (2010) The effects of corporate social responsibility on brand performance: The mediating effect of industrial brand equity and corporate reputation. Journal of Business Ethics 95(3): 457-469.

23. Miller D, M Dale (2013) Linking retailer corporate brand and environmental sustainability practices. Journal of Product and Brand Management 22(7): 437-443.

24. Poolthong Y, Mandhachitara R (2009) Customer expectations of CSR, perceived service quality and brand effect in Thai retail banking. International Journal of Bank Marketing 27(6): 408-427.

25. Sen S, Bhattacharya CB, Korschun D (2006) The role of corporate social responsibility in strengthening multiple stakeholder relationships: A field experiment. Journal of the Academy of Marketing Science 34(2): 158-166. 
(C) Comis work is licensed under Creative

BY DOI: 10.19080/CTFTTE.2020.05.555675
Your next submission with Juniper Publishers will reach you the below assets

- Quality Editorial service

- Swift Peer Review

- Reprints availability

- E-prints Service

- Manuscript Podcast for convenient understanding

- Global attainment for your research

- Manuscript accessibility in different formats

( Pdf, E-pub, Full Text, Audio)

- Unceasing customer service

Track the below URL for one-step submission https://juniperpublishers.com/online-submission.php 